\title{
RANCANG BANGUN INTERNET Of THINGS (Iot) UNTUK KALKULASI INTENSITAS KONSUMSI ENERGI (IKE)
}

\author{
Muhammad Triyo Rahmanto, Krismadinata \\ Teknik Elektro Industri, Jurusan Teknik Elektro, Fakultas Teknik Universitas Negeri Padang \\ Jl. Prof. Dr Hamka, Kampus UNP Air Tawar Padang 25131.Telp/Fax.(0751).7055644, 445998, \\ e-mail: muhammadtriyo31@gmail.com, krisma@ft.unp.ac.id
}

\begin{abstract}
ABSTRAK
Pada perancangan suatu gedung selain dirancang struktur bangunan juga melakukan perencanaan pemakaian energi dengan mengidentifikasi beban beban yang akan terpasang. Namun seiring berjalannya waktu dan masa perawatan serta penggantian peralatan listrik maka akan akan merubah terhadap beban yang telah direncanakan. SNI 03-6196-2000 adalah Pedoman yang digunakan dalam menghitung Efisiensi Penggunaan Energi Listrik. Alat yang di buat ini terdiri dari dua sistem yakni Sistem Utama dan Sistem Transmitter. Dengan objek yang diamati yakni pada ruangan labor EA8D dan Labor E61 Teknik Elektro, Fakultas Teknik, Universitas Negeri Padang. Sistem Transmitter berfungsi untuk membaca nilai IKE suhu, kelembaban dan intensitas pencahayaan yang ada pada ruang kemudian data dikirim ke Sistem Utama melalui Wireless. Sistem Utama berfungsi untuk membaca nilai IKE tegangan, arus dan energi yang terpakai (kWh). modul wifi ESP 826601digunakan Untuk mengirimkan data ke server. Pembacaan nilai dapat dilihat melalui halaman Website erc.unp.ac.id/ta. Hasil penelitian menunjukkan IKE masuk dalam kategori sangat efisien.
\end{abstract}

Kata Kunci : IKE, arduino Uno, ESP 8266, Wireless

\begin{abstract}
In the design of a building, in addition to being designed a building structure, it also conducts energy use planning by identifying the loads to be installed. However, over time and the maintenance period and the replacement of electrical equipment will change the planned load. SNI 03-6196-2000 is a guideline used in calculating the efficiency of the use of electrical energy. This device consists of two systems, the Main System and the Transmitter System. With the object being observed namely in the EA8D labor room and E61 Labor in Electrical Engineering, Faculty of Engineering, Padang State University. The Transmitter System functions to read IKE values of temperature, humidity and intensity of lighting in the room then data is sent to the Main System via Wireless. The Main System functions to read IKE values of voltage, current and energy used (kWh). wifi module ESP 8266-01 is used to send data to the server. Value reading can be seen through the Website page erc.unp.ac.id/ta. The results showed IKE included in the very efficient category.
\end{abstract}

Keywords: IKE, arduino Uno, ESP 8266, Wireless

\section{Pendahuluan}

Pada awal mula perancangan suatu gedung telah dihitung rencana pemakaian energi dengan pertimbangan fungsi dan kegunaanya dan berpatokan pada standar yang telah ditetapkan,. Namun seiring berjalannya waktu dan masa perawatan serta penggantian peralatan listrik maka akan akan merubah terhadap beban yang telah direncanakan di awal terutama berkaitan dengan beban penerangan dan pendingin ruangan bahkan penggunaan energi menjadi tidak efisien lagi. Metode yang digunakan untuk menganalisis efisiensi pemakaian energi listrik adalah metode konservasi energi. Dalam metoda ini akan menghitung tingkat konsumsi energi pada suatu gedung atau bangunan. Kemudian hasil yang didapatkan akan dibandingkan dengan standar yang ada dan mencari solusi untuk melakukan penghematan jika konsumsi energi melebihi standar yang ada berdasarkan parameter yang diukur [7].

Parameter yang menjadi rujukan untuk audit energi ialah suhu, kelembaban dan pencahayaan yang akan dibandingkan dengan pemakaian energi perluas bangunan atau 
$\mathrm{kWh} / \mathrm{m}^{2}$ [1]. Cara melakukan audit energi awal yakni identifikasi jenis dan fungsi bangunan, identifikasi informasi konsumsi energi dalam jangka waktu tertentu, menghitung nilai IKE dan menganalisisnya. Dalam melakukan audit energi dibutuhkannya data data mengenai pemakaian energi dan besarnya beban yang terpasang. Namun dilapangan disetiap fakultas tidak ada energi metering yang dapat merecord pemakaian listrik. Pemakian listrik masih di hitung secara global tingkat universitas. Penelitian lain data didapatkan masih melalui observasi langsung di lokasi dan mengelola melakukan audit secara manual sehingga saran yang di berikan harus berdasarkan observasi llangsung di lapangan dan belum dapat di pantau dari jarak jauh [5]. Untuk melakukan proses audit energi diperlukan data besarnya beban pemakaian energi ( $\mathrm{kWh})$. [3] suatu sistem telah dirancang sebagai alat ukur kWh meter satu fasa dengan sistem informasi secara online, sistem yang dibuat berupa $\mathrm{kWh}$ meter digital yang data terrecord pada database secara online.

Seiring dengan perkembangan teknologi internet maka data pemakaian energi dan data pengukuran parameter audit energi yang diperlukan akan di-record secara realtime dan disimpan pada database sehingga user dapat mengakses dari mana saja. Data yang diperoleh maka akan dibandingkan dengan standar audit energi SNI 2011 dan akan memberikan output pola konsumsi energi debagai rujukan bila ada perbaikan sistem. Dengan dibuatnya alat ini maka pengambilan data dalam proses audit energi dapat di observasi online

\section{Metode Penelitian}

Dalam proses pembuatan tugas akhir ini digunakan beberapa rujukan pada proses pembuatan alat agar dapat berfungsi untuk memonitoring Intensitas Konsumsi Energi

\subsection{Audit Energi}

Dalam melakukan perhitungan terhadap pemakaian energi listrik metode yang digunakan adalah metode konservasi energi. Dalam melakukan konservasi energi dibutuhkan teknik audit energi [7]. Perhitungan dalam menentukan audit energi yakni dengan menghitung Intensitas Konsumsi Energi (IKE) listrik. IKE yakni pembagian antara konsumsi energi listrik pada kurun waktu tertentu (bulan / tahun) per satuan luas bangunan gedung. Atau ditulis dengan rumus

$$
\begin{aligned}
& \operatorname{IKE}\left(\mathrm{kWh} / \mathrm{m}^{2}\right)= \\
& \frac{\mathrm{kWh} \text { total }(\mathrm{kWh} / \text { tahun })}{\text { (occRate } \mathrm{x} \text { Area Room })+(\text { Area Non Room })}(1)
\end{aligned}
$$

Hasil dari perhitungan nilai IKE akan disesuaikan dengan pedoman standar audit energi SNI 2011 seperti yang terlihat pada tabel 1 dengan menentukan kriteria ruangan yakni gedung ber-AC dan tidak . tebel IKE tersebut berpedoman pada perhitungan perbulan [4].

\section{Tabel 1. Tabel IKE Departemen Pendidikan Nasional Republik

\begin{tabular}{|c|c|c|}
\hline kriteria & $\begin{array}{l}\text { Ruang ber-AC } \\
\text { (kWh/m²/tahun) }\end{array}$ & $\begin{array}{l}\text { Ruang tidak ber- } \\
\text { AC (kWh/m²/tahun) }\end{array}$ \\
\hline $\begin{array}{l}\text { Sangat } \\
\text { Efisien }\end{array}$ & $50-95$ & $10-20$ \\
\hline Efisien & $95-145$ & $20-30$ \\
\hline $\begin{array}{l}\text { Cukup } \\
\text { Efisien }\end{array}$ & $145-175$ & - \\
\hline $\begin{array}{l}\text { Agak } \\
\text { Boros }\end{array}$ & $175-230$ & - \\
\hline Boros & $230-285$ & $30-40$ \\
\hline $\begin{array}{l}\text { Sangat } \\
\text { Boros }\end{array}$ & $285-450$ & $40-50$ \\
\hline
\end{tabular} Indonesia}

\subsection{Arduino Uno}

Arduino Board merupakan papan rangkaian sistem minimum yang menggunakan IC Atmega, produk ini bersifat open source. Untuk pemograman papan Arduino menggunakan software Arduino IDE (Integrated Development Environment). Dalam melakukan pemograman Arduino IDE dilengkapi dengan library $\mathrm{C} / \mathrm{C}++$.

\subsection{Sensor Arus}

Sensor arus yang digunakan adalah SCT 013 current transformer, CT sensor merupakan inti dari sebuah pengukuran arus listrik bolak balik, sensor arus SCT 013 yang mudah dicopot dan dipasang pada suatu beban rangkaian hanya dengan dipasang pada salah satu kabel saja. Dikarenakan menggunakan sistem non kontak terhadap rangkaian listrik yang juga disebut dengan sistem Non-Invasive.

\subsection{Sensor Tegangan}


Sensor tegangan yang digunakan adalah ZMPT 101B. Sensor ini memiliki prinsip kerja dengan menggunakan Potential Transformator atau transformator tegangan digunakan untuk menurunkan tegangan dengan perbandingan transformasi tertentu. Karena fungsinya untuk menurunkan tegangan, jumlah lilitan sekunder pada trafo tegangan lebih sedikit dibandingkan dengan jumlah lilitan primernya

\subsection{Sensor Suhu dan Kelembaban}

Sensor DHT11 merupakan sensor dengan kalibrasi sinyal digital yang mampu memberikan informasi suhu dan kelembaban. Sensor ini tergolong komponen yang memiliki tingkat stabilitas yang sangat baik.

\subsection{Sensor Intensitas Cahaya}

Sensor intensitas cahaya yang akan digunakan adalah BH1750. Sensor ini adalah sensor Digital Light, yang merupakan IC Sensor Ambient Light untuk antarmuka bus I2C. IC ini adalah cocok untuk mengukur data cahaya sekitar.

\subsection{Modul Wifi ESP8266}

Modul ESP8266-01 merupakan perangkat tambahan yang berfungsi agar Arduino dapat terhubung langsung dengan wifi dan membuat koneksi TCP/IP. Modul ini disupllay dengan tegangan 3,3VDC dengan tiga mode pengaturan yakni Station, Access Point dan Both (Keduanya).

\subsection{Flowchart dan Diagram blok}

Flowchat merupakan diagram alir yang mengilustrasikan alur atau proses kerja dari suatu sistem, Pada gambar 1 menjelaskan Diagram Kerja Alat secara keseluruhan, dua buah sistem yakni pada ruangan labor EA8D dan E61 Teknik Elektro, Fakultas Teknik, Universitas Negeri Padang. Kedua sistem harus terlebih dahulu terkoneksi dengan internet melalui router Wifi dan sistem akan membaca dan mengirimkan data ke server. Pada sisi server data akan di terima dan di tampung melalui (tambah.php) atau dalam file php yang dibuat kemudian pada halaman ini akan disimpan pada database system, semua parameter IKE yang di ukur akan masuk dan dikelola melalui Web sever. Hasilnya akan dapat dilihat melalui halaman Website dengan bantuan koneksi internet. Halaman website yang di gunakan sebagai interface ke user. pada gambar 2 dijelaskan proses sistem dalam melakukan monitoring IKE.

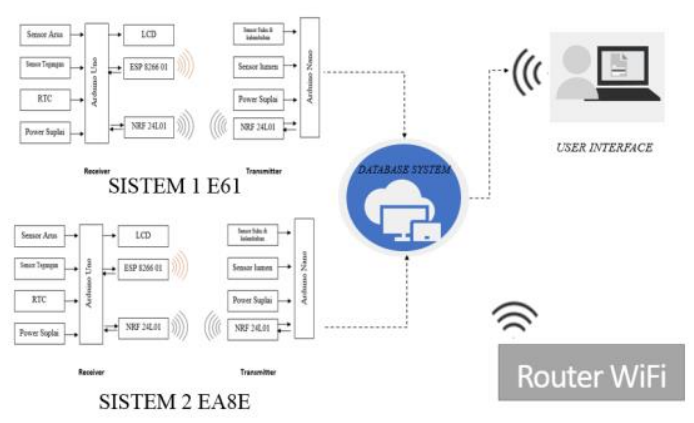

\section{Gambar 1. Diagram Kerja Alat secara keseluruhan}

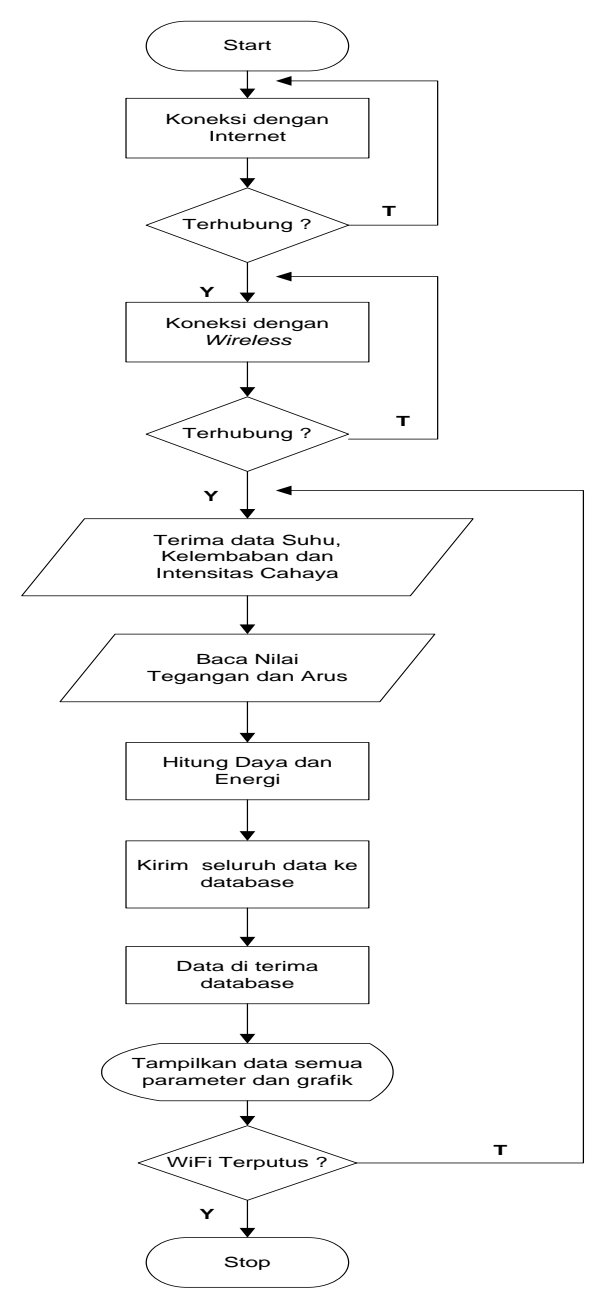

Gambar 2. Flowchart kerja Sistem 


\section{Hasil dan Pembahasan}

Alat atau Suatu sistem dapat dikategorikan bekerja dengan baik sesuai dengan perencanaannya apabila telah teruji sesuai fungsi kerja dari peralatan tersebut. Hasil pegujian menunjukkan hasil akhir perencanaan sesuai dengan kenyataan bahwa perangkat keras yang telah dibuat bisa bekerja dengan baik dan dapat dilakukan interface oleh user.

\subsection{Instrumen pengujian Alat}

\section{a. Multimeter Digital}

Multimeter ini berfungsi untuk menguji tegangan dari catu daya dan tegangan pada sensor tegangan, Multimeter yang digunakan adalah multimeter digital APPA109N.

b. AC Clamp Meter Fluke 373

Alat ukur ini memiliki spesifik arus sampe dengan 600A. Alat ukur ini digunakan Untuk mengukur arus pada sistem dan membandingkan dengan sensor SCT-013

\section{c. Digital LM-8000}

Alat ini memiliki fungsi sebagai pengukur kecepatan angin, persentasi kelembaban, suhu dan intensitas cahaya, pembacaan nilai ditampilkan secara digital. Digital LM-8000 digunakan untuk pembanding pembacaan sensor suhu dan kelembaban dari DHT 11 dan pembanding pembacaan intensitas cahaya dari sensor BH1750

\subsection{Pengujian dan Analisa Hardware}

a. Catu Daya 9 VDC

Pengujian catu daya dilakukan menggunakan multimeter digital APPA $109 \mathrm{~N}$. Tegangan yang dikeluarkan dari catu daya yaitu 9 VDC.

Tabel 2. Pengujian catu daya

\begin{tabular}{|l|l|}
\hline Titik Pengukuran & $\begin{array}{l}\text { Hasil } \\
\text { Pengukuran }\end{array}$ \\
\hline $\begin{array}{l}\text { Tegangan sisi primer } \\
\text { transformator }\end{array}$ & $232,8 \mathrm{VAC}$ \\
\hline $\begin{array}{l}\text { Tegangan sisi } \\
\text { sekunder } \\
\text { transformator }\end{array}$ & $10,427 \mathrm{VAC}$ \\
\hline $\begin{array}{l}\text { Tegangan Output } \\
\text { Dioda Bridge }\end{array}$ & $12,413 \mathrm{VDC}$ \\
\hline $\begin{array}{l}\text { Tegangan Output } \\
\text { Regulator }\end{array}$ & $8,982 \mathrm{VDC}$ \\
\hline
\end{tabular}

Berdasarkan dari table 2 didapatkan tegangan keluaran Catu Daya sebesar 8,982 VDC. Persentase kesalahan yang terjadi yaitu hanya sebesar 0,2\%. Ditinjau dari data sheet IC LM7809, maka persentase kesalahan masih dalam toleransi karena IC LM7809 memiliki toleransi $\pm 4 \%$.

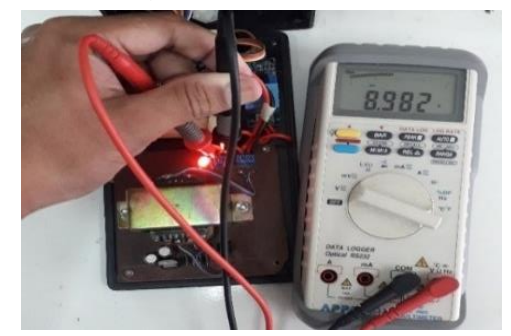

Gambar 1. Pengujian Catu Daya 9 VDC

b. Sensor Suhu

Nilai pembacaan sensor akan dibandingkan dengan pembacaan thermocouple thermometer. Hasil pengukuran dan pengujian suhu terlihat pada tabel 5 .

Tabel 3.Pengujian Sensor suhu

\begin{tabular}{|l|l|c|c|c|}
\hline No & $\begin{array}{l}\text { Suhu } \\
\text { DHT11 } \\
\left({ }^{\circ} \mathrm{C}\right)\end{array}$ & $\begin{array}{c}\text { Suhu } \\
\text { Thermocouple } \\
\text { Thermometer } \\
\left({ }^{\circ} \mathrm{C}\right)\end{array}$ & $\begin{array}{c}\text { Selisin } \\
\text { sensor } \\
\text { dan } \\
\text { alat } \\
\text { ukur } \\
\left({ }^{\circ} \mathrm{C}\right)\end{array}$ & $\begin{array}{c}\text { Error } \\
(\%)\end{array}$ \\
\hline 1 & 19 & 19,7 & 0.7 & 3,6 \\
\hline 2 & 19 & 19,3 & 0.3 & 1,6 \\
\hline 3 & 18 & 18,2 & 0.2 & 1,1 \\
\hline 4 & 21 & 21,8 & 0.8 & 3,6 \\
\hline 5 & 23 & 23,4 & 0.4 & 1,7 \\
\hline 6 & 27 & 26,5 & 0.5 & 1,9 \\
\hline 7 & 25 & 24,4 & 0.6 & 2,5 \\
\hline 8 & 25 & 24,3 & 0.7 & 2,9 \\
\hline 9 & 28 & 28,6 & 0.6 & 2 \\
\hline 10 & 29 & 29,6 & 0.6 & 2 \\
\hline
\end{tabular}

Pada tabel 3 dapat dilihat bahwa adanya perbedaan pembacaan suhu,hal ini disebabkan oleh tingkat akurasi yang berbeda. Selisih pengukuran suhu paling besar yaitu $\left(0.8^{\circ} \mathrm{C}\right)$ dan rata-rata kesalahan sebesar $2.29 \%$, maka dapat disimpulakan bahwa sensor dapat bekerja dengan baik.

\section{c. Sensor Kelembaban}

Nilai pembacaan sensor akan dibandingkan dengan pembacaan alat ukur digital Humidity. 
Tabel 4. Pengujian Sensor Kelembaban

\begin{tabular}{|l|c|c|c|c|}
\hline No & $\begin{array}{c}\text { Kelembaban } \\
\text { DHT11 (\%) }\end{array}$ & $\begin{array}{c}\text { Kelembaban } \\
\text { Digital } \\
\text { Humidity(\%) }\end{array}$ & $\begin{array}{c}\text { Selisih } \\
\text { sensor } \\
\text { dan } \\
\text { alat } \\
\text { ukur } \\
(\%)\end{array}$ & $\begin{array}{c}\text { Error } \\
(\%)\end{array}$ \\
\hline 1 & 88 & 90,2 & 2.2 & 2,44 \\
\hline 2 & 88 & 89,7 & 1.7 & 1,90 \\
\hline 3 & 86 & 86,5 & 0.5 & 0,58 \\
\hline 4 & 80 & 80,6 & 0.6 & 0,74 \\
\hline 5 & 74 & 74,6 & 0.6 & 0.80 \\
\hline 6 & 72 & 73,2 & 0.5 & 1,64 \\
\hline 7 & 74 & 74,9 & 0.9 & 1,20 \\
\hline 8 & 70 & 71,3 & 0.3 & 1,82 \\
\hline 9 & 69 & 68,5 & 0.5 & 0,73 \\
\hline 10 & 60 & 61,0 & 1 & 1,64 \\
\hline
\end{tabular}

Pada table 4 diatas dapat dilihat selisih pengukuran paling besar yaitu $(2,2 \%)$ dan rata-rata kesalahan sebesar $1.34 \%$, maka dapat disimpulakan bahwa sensor DHT11 dapat bekerja dengan baik.

\section{d. Sensor Intensitas Cahaya}

Pengukuran ini digunakan untuk mencari intensitas cahaya pada bidang meja kerja dan di bandingkan dengan lux meter digital. Data seperti terlihat di table 5

Tabel 5. Pengujian Sensor Intensitas Cahaya

\begin{tabular}{|l|c|c|c|l|}
\hline No & $\begin{array}{c}\text { Sensor } \\
\text { BH1750 } \\
\text { (Lux) }\end{array}$ & $\begin{array}{c}\text { Alat ukur } \\
\text { Luxmeter } \\
\text { (Lux) }\end{array}$ & $\begin{array}{c}\text { Selisih } \\
\text { Alat ukur } \\
\text { dan } \\
\text { sensor }\end{array}$ & $\begin{array}{l}\text { Error } \\
(\%)\end{array}$ \\
\hline 1 & 834 & 852 & 18 & 2,11 \\
\hline 2 & 817 & 836 & 19 & 2,27 \\
\hline 3 & 803 & 826 & 23 & 2,88 \\
\hline 4 & 792 & 806 & 14 & 1,74 \\
\hline 5 & 767 & 780 & 13 & 1,67 \\
\hline 6 & 645 & 652 & 7 & 1,07 \\
\hline 7 & 629 & 622 & 7 & 1,12 \\
\hline 8 & 589 & 600 & 11 & 1,83 \\
\hline 9 & 438 & 450 & 12 & 2,65 \\
\hline 10 & 432 & 443 & 11 & 2,48 \\
\hline
\end{tabular}

Dari tabel 4 di atas dapat dilihat error dari sensor tersebut adalah yang paling besar 2,88 \%. Menurut peneliti error tersebut masih wajar dan dapat jadi acuan dalam pengambilan data

\section{e. Sensor Tegangan}

Pengujian dilakukan dengan cara mengukur tegangan dari voltage regulator menggunakan Sensor Tegangan dan multimeter digital. Perbandingan pembacaan sensor seperti terlihat pada tabel 6.

Tabel 6. Pengujian Sensor Intensitas Cahaya

\begin{tabular}{|l|c|c|c|c|}
\hline No. & $\begin{array}{c}\text { Sensor } \\
\text { Tegangan } \\
\text { (V) }\end{array}$ & $\begin{array}{c}\text { Alat ukur } \\
\text { Voltmeter(V) }\end{array}$ & $\begin{array}{c}\text { Selisih } \\
\text { sensor } \\
\text { dan } \\
\text { alat } \\
\text { ukur } \\
(\mathrm{V})\end{array}$ & $\begin{array}{l}\text { Error } \\
(\%)\end{array}$ \\
\hline 1 & 223,51 & 223,0 & 0,51 & 0,23 \\
\hline 2 & 224,33 & 223,0 & 1,33 & 0,59 \\
\hline 3 & 225,53 & 225,4 & 0,13 & 0,05 \\
\hline 4 & 226,12 & 225,4 & 0,28 & 0,12 \\
\hline 5 & 227,75 & 227,2 & 0,55 & 0,24 \\
\hline 6 & 227,81 & 227,2 & 0,61 & 0,26 \\
\hline 7 & 230,64 & 230,2 & 0,44 & 0,19 \\
\hline 8 & 230,74 & 230,2 & 0,54 & 0,23 \\
\hline 9 & 234,41 & 234,2 & 0,21 & 0,09 \\
\hline 10 & 234,79 & 234,2 & 0,59 & 0,25 \\
\hline
\end{tabular}

Pada table 6 dapat dilihat selisih pengukuran paling besar yaitu 1,33 Volt AC dan rata-rata kesalahan 0,23\%, maka disimpulkan bahwa Sensor Tegangan masih dalam batas dan dapat bekerja dengan baik.

\section{f. Sensor Arus}

Sensor Arus SCT-013 digunakan untuk mengukur arus dan hasil pengukuran dibandingkan dengan alat ukur Tang Amper Fluke 373. Hasil pengukuran seperti terlihat di tabel 7.

Tabel 7. Pengujian Sensor Intensitas Arus

\begin{tabular}{|l|l|l|l|l|}
\hline No. & $\begin{array}{l}\text { Sensor } \\
\text { Arus } \\
\text { (A) }\end{array}$ & $\begin{array}{l}\text { Alat ukur } \\
\text { Amperemeter } \\
\text { (A) }\end{array}$ & $\begin{array}{l}\text { Selisih } \\
\text { sensor } \\
\text { dan } \\
\text { alat } \\
\text { ukur } \\
\text { (A) }\end{array}$ & $\begin{array}{l}\text { Error } \\
(\%)\end{array}$ \\
\hline 1 & 6,06 & 6,0 & 0,06 & 1 \\
\hline 2 & 6,44 & 6,5 & 0,06 & 0.92 \\
\hline 3 & 6,39 & 6,2 & 0,19 & 3,06 \\
\hline 4 & 8,21 & 8,1 & 0,11 & 1,36 \\
\hline 5 & 7,45 & 7,2 & 0,25 & 3,47 \\
\hline 6 & $8,, 99$ & 8,8 & 0,19 & 2,15 \\
\hline 7 & 7,39 & 7,3 & 0,09 & 1,23 \\
\hline
\end{tabular}




\begin{tabular}{|l|l|l|l|l|}
\hline 8 & 9,55 & 9,5 & 0,05 & 0.53 \\
\hline 9 & 8,07 & 8,0 & 0,07 & 0,88 \\
\hline 10 & 8,43 & 8,3 & 0,13 & 1,56 \\
\hline
\end{tabular}

Berdasarkan pengujian besar ratarata kesalahan sebesar $1,6 \%$, selisih tersebut masih dalam batas dan dapat disimpulkan bahwa sensor arus dapat bekerja dengan baik.

\section{g. Konektivitas Wireless}

Pengujian modul NRF24101 bertujuan untuk mengetahui apakah modul NRF24101 dapat berkomunikasi antara Sistem Utama dan Sistem Transmiter. Data hasil pengujian seperti yang terlihat pada tabel 8 .

Tabel 8. Pengujian Konektivitas

\begin{tabular}{|l|l|l|l|}
\hline No & $\begin{array}{l}\text { Jarak } \\
\text { (meter) }\end{array}$ & kondisi & Status \\
\hline 1 & 1 & Terhalang & Terhubung \\
\cline { 3 - 4 } & & Tak Terhalang & Terhubung \\
\hline 2 & \multirow{2}{*}{10} & Terhalang & Terhubung \\
\cline { 3 - 4 } & & Tak Terhalang & Terhubung \\
\hline 3 & \multirow{2}{*}{20} & Terhalang & Terhubung \\
\cline { 3 - 4 } & & Tak Terhalang & Terhubung \\
\hline 4 & \multirow{2}{*}{30} & Terhalang & Terhubung \\
\cline { 3 - 4 } & & Tak Terhalang & Terhubung \\
\hline 5 & \multirow{2}{*}{40} & Terhalang & Terhubung \\
\cline { 3 - 4 } & & Tak Terhalang & Terhubung \\
\hline 6 & \multirow{2}{*}{50} & Terhalang & Terhubung \\
\cline { 3 - 4 } & & Tak Terhalang & Terhubung \\
\hline 7 & \multirow{2}{*}{55} & Terhalang & Terputus \\
\cline { 3 - 4 } & & Tak Terhalang & Terhubung \\
\hline
\end{tabular}

Hasil pengujian menunjukkan bahwa modul NRF24101 masih bisa menerima data sampai jarak $55 \mathrm{~m}$.

\section{h. Manajemen Database}

Pengujian dilakukan dengan melakukan pengiriman perintah menggunakan metode GET pada aplikasi POSTMAN. Dengan memasukkan interuksi sebagai berikut http:/erc.unp.ac.id//api/insert1.php?temp=2 9.00\&hum $=71.00 \&$ lux $=745.00$

$\&$ volt $=211.00 \& \mathrm{amp}=13.00 \& \mathrm{watt}=14.00 \&$ $\mathrm{kwh}=16.00$. setelah itu klik send dan akan muncul respon dari sistem pengujian ini seperti yang terlihat pada gambar 4 .

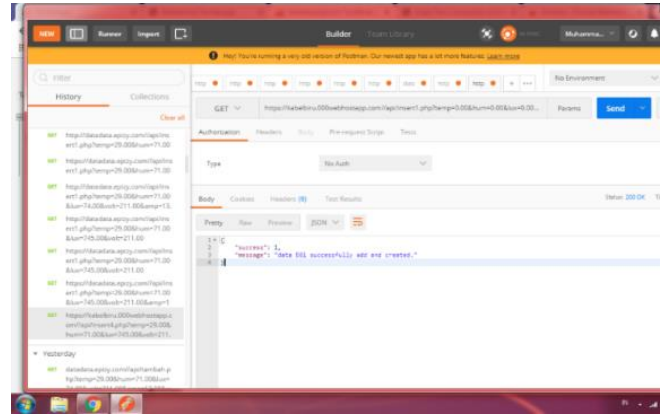

Gambar 2. Pengujian Manajemen Database

Hasil pengujian pada gambar 4 menunjukkan respon dari sistem akan menghasilkan respon 1 yang artinya sukses terkirim. Database yang kita setting telah sukses menerima data dan akan dimasukkan kedalam tabel.

\section{i. Konektivitas Pengiriman Data}

Pengujian dilakukan dengan memberikan akses ESP8266 untuk terhubung ke Wifi yang tersedia dengan melakukan inisialisasi ssid dan password wifi pada pemograman Arduino.

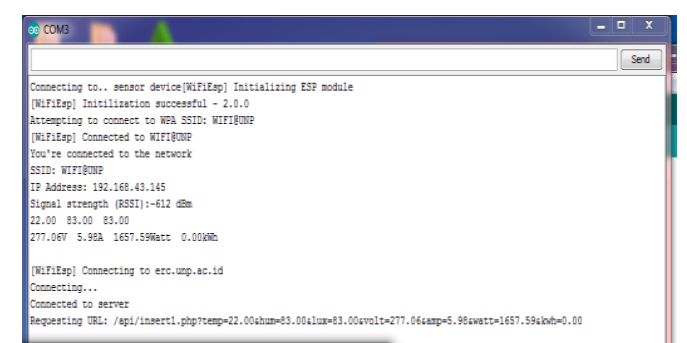

Gambar 3. Hasil konektivitas Pengiriman data

Dari hasil percobaan maka ESP akan mencoba terkoneksi dengan Wifi yang telah diseting dengan respon seperti pada gambar 5. Setelah Wifi terkoneksi maka akan terlihat status dari koneksi pada serial monitor dan akan memulai interuksi requesting URL untuk mengirimkan data ke database

\subsection{Pembahasan Intensitas Konsumsi Energi}

Labor E61 memiliki luas

Adapun tampilan web dari alat seperti pada gambar 3.hasil tampilan menunjukkan nilai parameter IKE yang dikirim dari sistem. 


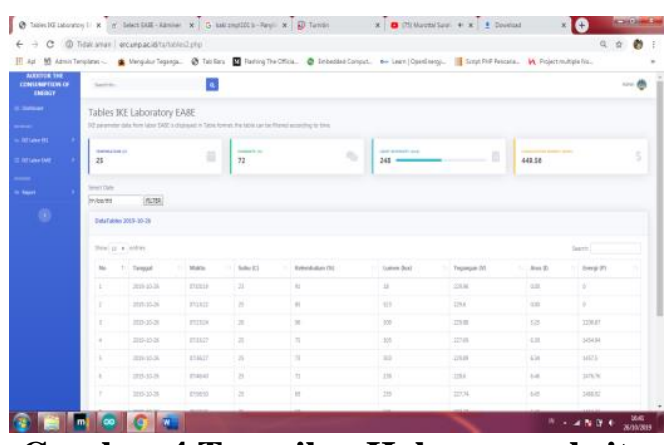

Gambar 4.Tampilan Halaman website

Spesifikasi labor E61

Konsumsi energi selama satu bulan (Oktober) adalah sebesar kWh. Dengan luas $\mathrm{m}^{2}$. Maka dapat dilakukan perhitungan sebagai berikut

a. Perhitungan energi Pertahun

$=388,16 \mathrm{kWh} \times 12$ bulan/tahun

$=4.657,92 \mathrm{kWh} /$ tahun

b. Besar intensitas konsumsi Energi listrik

$$
\begin{aligned}
& =4.657,92 \mathrm{kWh} / 105,6 \\
& =44,10 \mathrm{kWh} / \mathrm{m}^{2} / \text { tahun }
\end{aligned}
$$

Berdasarkan tabel 1 standar IKE, maka hasil analisis IKE E61 masih dalam kategori Sangat Efisien.

Spesifikasi labor EA8E

Konsumsi energi selama satu bulan (Oktober) adalah sebesar kWh. Dengan luas $\mathrm{m}^{2}$. Maka dapat dilakukan perhitungan sebagai berikut

a. Perhitungan energi Pertahun $=451,58 \mathrm{kWh} \times 12$ bulan $/$ tahun $=5.418,96 \mathrm{kWh} / \mathrm{tahun}$

b. Besar intensitas konsumsi Energi listrik

$=5.418,96 / 74,88$

$=72,36 \mathrm{kWh} / \mathrm{m}^{2} /$ tahun

Berdasarkan tabel 1 standar

IKE, maka hasil analisis IKE EA8E masih dalam kategori Sangat Efisien.

\section{Kesimpulan}

Setelah mengamati dan membahas mengenai sistem dalam melakukan monitoring IKE maka ditarik kesimpulan yaitu:

a. Program mikrokontroler dan web server yang telah dibangun dapat berfungsi sesuai dengan perancangan yang diinginkan yaitu pada pengujian program mikrokontroler dapat menerima data dari sistem transmiter dan memebeca parameter IKE serta mengirimkan data dan data dapat di kelola di web sesuai perancangan.

b. Hardware yang telah dibangun dapat berfungsi sesuai dengan perancangan yaitu pada pengujian, mikrokontroler sebagai pusat pengendali mulai dari pembacaan sensor, penerimaan data dari transmiter serta mengirim data ke web server

c. Hasil penelitian mengenai IKE pada objek menunjukkan bahwa IKE labor E61 dan EA8E masuk dalam kategori sangat efisien. Sedangkan untuk intensitas cahaya di kedua ruangan objek masih perlu di tingkatkan menjadi 500 lux sesuai dengan fungsi ruangan sebagai laboratorium.

\section{DAFTAR PUSTAKA}

[1] Pasisarha, Daeng Supriyadi, 2012.Evaluasi IKE melalui Audit Awal Energi Listrik di Kampus Polines. Politeknik Negeri Semarang. Semarang

[2] Pedoman Pelaksanaan Konservasi Energi dan Pengawasannya di Lingkungan DEPDIKNAS, Bagian Proyek Pelaksanaan Efisiensi Energi DEPDIKNAS, Jakarta, 2002.

[3] Ramadan, Dadan Nur. 2015 Rancang Bangun dan Implementasi Alat Ukur dan Sistem Informasi pada Listrik Satu Fasa. Universitas Telkom

[4] SNI standar Nasional Indonesia bagian proyek efisiensi energi DEPDIKNAS, Jakarta, 2001

[5] Suhendar. 2013. Audit Sistem Pencahayaan dan Sistem Pendingin Ruangan di Gedung Rumah Sakit Umum Daerah (RSUD) Cilegon. Jurnal SENTRUM vol.2 , No.2, Desember 2013. Teknik Elektro Universitas Sultan Agung Tirtayasa Cilegon.

[6] Septian, Deri.2013. Audit Energi dan Analisa Peluang Hemat Energi Pada Bangunan Gedung PT. X. Jurnal Aptek. Universitas pasir pengaraian

[7] Untoro, jati. 2014. Audit Energi dan Analisa Penghematan Konsumsi 
Energi pada Sistem Peralatan Listrik di Gedung Pelayanan Unila. Teknik Elektro Unila. Bandar Lampung

\section{Biodata Penulis}

Muhammad Triyo Rahmanto, lahir di Duri, 21 Februari 1996. Sedang menempuh jenjang sarjana pada Program Studi Teknik Elektro Industri di jurusan Teknik Elektro FT UNP.

Krismadinata, lahir di Padang, 11 September 1977. Lulus dengan gelar Sarjana Tenik dari Universitas Negeri Andalas tahun 2000. Memperoleh gelar Master of Technology dari Institut Teknologi Bandung (ITB) tahun 2004, lulus S3 di Universiti Malaya pada tahun 2012. 